\title{
Oxidants are dispensable for HIF1a stability in hypoxia
}

Amit Kumar ${ }^{1,2,3}$, Manisha Vaish ${ }^{1,4}$, Saravanan S. Karuppagounder ${ }^{1,2,3}$, Irina Gazaryann ${ }^{5}$ John W. Cave ${ }^{1,2,3}$, Anatoly A. Starkov², ${ }^{2}$, Elizabeth T. Anderson ${ }^{6}$, Sheng Zhang $^{6}$, John T. Pinto ${ }^{7}$, Austin Rountree ${ }^{8}$, Wang Wang ${ }^{9}$, lan R. Sweet ${ }^{8}$ and Rajiv R.

$$
\operatorname{Ratan}^{1,2,3, *}
$$

${ }^{1}$ Burke Neurological Institute, White Plains, NY, 10605, USA ${ }^{2}$ Brain and Mind Research Institute and ${ }^{3}$ Department of Neurology, Weill Medical College of Cornell University, New York, 10016, USA ${ }^{4}$ Department of Pharmacological Sciences, Icahn School of Medicine at Mount Sinai, New York, 10029, USA

${ }^{5}$ Department of Anatomy and Cell Biology, New York Medical College, Valhalla, NY, 10595, USA

6Institute for Biotechnology, Cornell University, Ithaca, NY, 14853, USA

${ }^{7}$ Department of Biochemistry and Molecular Biology, New York Medical College, Valhalla, NY, 10595, USA

${ }^{8}$ Department of Medicine, University of Washington, Seattle, WA, 98108, USA ${ }^{9}$ Department of Pain and Anesthesiology, University of Washington, Seattle, WA, 98195, USA

Correspondence should be addressed to:

${ }^{*}$ Rajiv R. Ratan M.D., Ph.D.

Burke Neurological Institute at Weill Cornell Medicine

785 Mamaroneck Avenue

White Plains, NY, 10605, USA

Email: rrr2001@med.cornell.edu

Phone: 914-597-2225 


\section{Abstract}

Hypoxic adaptation mediated by HIF transcription factors has been shown to require mitochondria. Current models suggest that mitochondria regulate oxygen sensor (HIF prolyl hydroxylase) activity and HIF1 $\alpha$ stability during hypoxia by either increasing mitochondrial peroxide as a second messenger or by serving as oxygen consumers that enhance the kinetics of cytoplasmic oxygen reduction. Here, we address the role of mitochondrial peroxide specifically in regulating HIF1a stability. We use state-of-the-art tools to evaluate the role of peroxide and other reactive oxygen species (ROS) in regulating HIF1 $\alpha$ stability. We show that antioxidant enzymes are not homeostatically induced nor are peroxide levels increased in hypoxia. Forced expression of diverse antioxidant enzymes, all of which diminish peroxide, had disparate effects on HIF1a protein stability. Reduction of lipid peroxides by glutathione peroxidase-4 or superoxide by mitochondrial SOD failed to influence HIF1 $\alpha$ protein stability. These data showed that mitochondrial, cytosolic and lipid ROS are dispensable for HIF1a stability and should affirm therapeutic efforts to activate the HIF pathway in disease states by HIF prolyl hydroxylase inhibition.

\section{Keywords}

Hypoxia, Mitochondria, Peroxide, Reactive oxygen species, HIF1a stability, $S$ glutathionylation, VHL, HIF PHDs, Oxygen, Ischaemia, Cancer, Stroke 


\section{Introduction}

Over the past decade, our ability to monitor and manipulate reactive oxygen species (ROS) has grown enormously. These technological advances provide a novel view on how ROS interact with cells to modulate function. Specifically, ROS such as peroxide can act as cellular messengers. Messenger functions for ROS reflect their tight spatial control within cells. The tight spatial control of ROS has enabled their critical roles in growth factor signalling, inflammation, and regeneration (Hameed et al., 2015; Jain et al., 2013; Lei \& Kazlauskas, 2014). Specific signalling roles for ROS are facilitated by the existence of motifs in proteins such as phosphatases that render these proteins specifically susceptible to redox modulation (Bae et al., 1997; Lee, Kwon, Kim, \& Rhee, 1998; Salmeen et al., 2003).

An important area of biology where ROS signalling has been highly investigated but where no consensus has emerged is hypoxic adaptation. Seminal work from the Semenza, Kaelin and Ratcliffe groups has demonstrated that when oxygen tension falls below a critical threshold, that a family of enzymes dependent on oxygen, iron and 2oxoglutarate known as the HIF Prolyl Hydroxylases (HIF PHDs) reduce their activity, leading to diminished hydroxylation of the alpha subunit of HIF transcription factors (Epstein et al., 2001; Ivan et al., 2002; Ivan et al., 2001; Jaakkola et al., 2001; Maxwell et al., 1999; Semenza \& Wang, 1992; Wang, Jiang, Rue, \& Semenza, 1995; Wang \& Semenza, 1993). Diminished HIF1a hydroxylation reduces recruitment of a key E3 ubiquitin ligase, the von Hippel Lindau (VHL) protein, and this allows HIF1a to avoid proteasomal degradation. Stabilised HIF1 $\alpha$ dimerises with its constitutively active partner to bind to hypoxia response elements in a coordinate gene cassette that leads to hypoxic 
adaptation at a cellular, local and systemic level (Jiang, Rue, Wang, Roe, \& Semenza, 1996; Wang et al., 1995; Wood, Gleadle, Pugh, Hankinson, \& Ratcliffe, 1996)). HIF transcription factors have been implicated in limiting damage to the kidney, heart and brain and in the progression of a host of cancers, as well as pulmonary fibrosis. Therefore, understanding the role of ROS in HIF1a-mediated adaptation has numerous clinical implications (Bryant et al., 2016; Conde et al., 2012; Semenza, 2012, 2014; Sheldon, Lee, Jiang, Knox, \& Ferriero, 2014; Weidemann et al., 2008).

Previous studies have shown that the dose response of HIF1a stability that would progressively lower oxygen concentrations required other factors besides oxygen to regulate HIF PHD activity (Bell et al., 2007; Brunelle et al., 2005; Chandel et al., 2000; Mansfield et al., 2005). Using what were then state-of-the-art tools to monitor ROS, earlier researchers showed that ROS were increasing during hypoxia and that pharmacological tools that nullified this increase in ROS diminished HIF1a stability (Chandel et al., 2000). A compelling model emerged that hypoxia increases the flux of electrons via Rieske ironsulphur (Fe-S) cluster proteins in complex III, and this leads to an increase in mitochondrial ROS generation via the ubiquinone binding site near the outer leaflet of the inner mitochondrial membrane (the Qo site) (Bell et al., 2007). Peroxide generated at this site could then diffuse through the outer mitochondrial membrane to inhibit HIF PHDs by either direct redox modulation of HIF PHDs (Bell et al., 2007) or by activation of established redox sensitive p38 MAP kinase signalling (Emerling et al., 2005).

Since its inception, the concept of a role for mitochondria in HIF signalling, as established by Chandel and Schumacker, has been validated (Agani, Pichiule, Chavez, \& LaManna, 2000; Mansfield et al., 2005; Taylor, 2008). However, an alternate ROS- 
independent view of how mitochondria regulate HIF1 $\alpha$ stability in hypoxia has also been advanced. Pharmacological inhibition of electron transport chain (ETC) complexes or genetic knockdown of Rieske Fe/S proteins or cytochrome c not only inhibit mitochondrial ROS production (Bell et al., 2007; Brunelle et al., 2005; Chandel et al., 2000; Mansfield et al., 2005), it also inhibits oxygen consumption. In this distinct scheme, inhibition of the ETC function would alter the kinetics of reduction of cytosolic oxygen levels. Indeed, several groups have provided data supporting the importance of respiratory chain-driven mitochondrial oxygen consumption in dictating cellular oxygen gradients. These gradients have been hypothesised to reduce oxygen concentrations to levels required to inhibit the enzymatic activity of oxygen-dependent HIF PHDs—-the key upstream regulator of HIF1 $\alpha$ stability (Chua et al., 2010; Doege, Heine, Jensen, Jelkmann, \& Metzen, 2005; Hagen, Taylor, Lam, \& Moncada, 2003).

In this manuscript, we leverage a host of complementary approaches that support the conclusion that peroxide is a dispensable mediator of regulated HIF1 $\alpha$ stability in hypoxia. Unexpectedly, our results suggest that HIF1a stability in hypoxia is not oxidantinitiated.

\section{Results}

\section{Antioxidant enzymes are not homeostatically induced in hypoxia}

Increases in ROS that are sufficient for signalling or toxicity trigger homeostatic transcriptional increases in antioxidant enzymes (Christman, Storz, \& Ames, 1989). To assess whether hypoxia results in similar homeostatic increases in antioxidant protein expression, we exposed human neuroblastoma (SH-SY5Y) cells to hypoxia for $8 \mathrm{~h}$ and 
measured protein expression levels of peroxisomal, cytosolic and mitochondrial antioxidant enzymes, including catalase, glutathione peroxidase-1 (GPX1), glutathione peroxidase-4 (GPX4), MnSOD and peroxiredoxin-3 (PRDX3) (Figure 1A). The $8 \mathrm{~h}$ time point was chosen to monitor homeostatic changes in antioxidant enzymes because this would be $6 \mathrm{~h}$ following observable HIF1a stability in hypoxia in SH-SY5Y cells, which provides adequate time for homeostatic increases to initiate transcriptional or posttranscriptional adaptations. At the $8 \mathrm{~h}$ time point, neither the protein level of the peroxisomal antioxidant catalase nor the antioxidants present in both cytosol and mitochondria, such as GPX1 and GPX4, showed any change in hypoxia with normalisation to actin (Figures 1B and 1C). However, since hypoxia induces HIF1 $\alpha-$ dependent mitophagy (Aminova, Siddiq, \& Ratan, 2008; Zhang et al., 2008), mitochondrial mass is decreased with increasing duration of hypoxia and includes decreases in mitochondrial DNA and proteins. Accordingly, we normalised distinct mitochondrially targeted antioxidant enzymes to the level of citrate synthase, a mitochondrial protein. When normalised to citrate synthase, the expression levels of mitochondrial antioxidants, such as MnSOD and PRDX3, also did not change during hypoxia (Figures 1D and 1E). We then endeavoured to establish whether these findings apply to non-transformed cells by studying the expression levels of antioxidant enzymes in hypoxia in primary neurons. Similar to the case in neuroblastoma cells, the antioxidant enzyme levels did not change in post-mitotic neurons during hypoxia (Figures 1F-1I). Taken together, these findings suggest that ROS levels do not increase during hypoxia.

\section{Peroxide levels do not increase during hypoxia}


HyPer is a fusion protein composed of the peroxide-sensitive domain of the prokaryotic transcription factor, OxyR, and yellow fluorescent protein, which is a reporter for cellular peroxide (Belousov et al., 2006). This reporter is not only sensitive and specific, but its activity is also ratiometric, so this factors out any differences in fluorescence due to cell geometry, path length and reporter concentration. Prior studies have shown that enhanced $\mathrm{pH}$ buffering of the extracellular medium alleviates the putative effects of acidic $\mathrm{pH}$ during hypoxia on the reporter and that fluorescence ratios in cells can be calibrated to known peroxide concentrations (Neal et al., 2016).

We monitored changes in the level of hydrogen peroxide $\left(\mathrm{H}_{2} \mathrm{O}_{2}\right)$ using real-time imaging of rat pancreatic islet cells under hypoxia with strong $\mathrm{pH}$ buffering. We used pancreatic islet cells, rather than neurons or neuron-like cells, for this initial analysis because mitochondrial peroxide in pancreatic islet cells increases in response in extracellular glucose levels, as measured using HyPer imaging. Elevated glucose can therefore be used as a positive control for mitochondrial peroxide increases. Elevated glucose also increases insulin release in beta islet cells, thereby enabling insulin release assays to establish cell viability in the absence of peroxide changes during hypoxia. Similar real-time measurements of cell function are not readily available in primary neurons or SH-SY5Y neuroblastoma cells.

Prior studies have also established that glucose-induced peroxide formation is derived from the mitochondria. Specifically, increased expression of mitochondrial catalase lowered the glucose-induced HyPer signals (catalase scavenges peroxide), as did reduced expression of mitochondrial SOD (MnSOD; the enzyme that converts superoxide to peroxide) (Neal et al., 2016). Finally, the signalling levels of peroxide 
measured by HyPer are 1/20th those of the peroxide levels required for toxicity (Neal et al., 2016), thereby confirming the sensitivity of the peroxide measurements using HyPer in this cell type. Before assaying peroxide in hypoxia, we verified that $2 \mathrm{~h}$ of hypoxia induced the established HIF1a target genes Kdm6b and Bnip3 in islet cells in our flow culture system (Figures $1 \mathrm{~J}$ and $1 \mathrm{~K}$ ) (Choudhry \& Harris, 2018). This time point was selected to evaluate the role of peroxide in mediating the earliest changes in HIF1 $\alpha$ stability in hypoxia because it occurs well before mitochondrial autophagy is induced (Figure 1).

Accordingly, based on the sensitivity and specificity of the reporter assay, we were confident that mitochondrial peroxide was measureable in islet cells should it increase during hypoxia. We measured $\mathrm{H}_{2} \mathrm{O}_{2}, \mathrm{NAD}(\mathrm{P}) \mathrm{H}$ and insulin secretion rates simultaneously as a function of glucose concentration for $2 \mathrm{~h}$ under hypoxic conditions $\left(1 \% \mathrm{O}_{2}\right)$ (Figure 1L). Increasing the glucose concentration from $3 \mathrm{mM}$ to $20 \mathrm{mM}$ elicited the expected increases in peroxide, decreases in NADPH levels and insulin secretion rates under normoxia. Exposure of islet cells under the same glucose concentrations $(20 \mathrm{mM})$ to $1 \%$ oxygen resulted in a decrease in $\mathrm{H}_{2} \mathrm{O}_{2}$ of more than $80 \%$. This reduction occurred in the midst of increased $\operatorname{NAD}(\mathrm{P}) \mathrm{H}$ levels. $\operatorname{NADP}(\mathrm{H})$ likely increased due to its diminished utilisation by the mitochondrial electron transport chain. Glucose-stimulated insulin secretion decreased by about $50 \%$ in response to hypoxia, but it remained well above the unstimulated rates, indicating that the islets remained functional throughout the study. Indeed, restoring steady state $\mathrm{O}_{2}$ levels (20\%) resulted in the expected increases in peroxide and insulin secretion, with concomitant decreases in $\mathrm{NAD}(\mathrm{P}) \mathrm{H}$, indicating that 
hypoxia delivered under the conditions of our experiments is not toxic to islet cells (Figure 1L).

We then endeavoured to establish the generalisability of these findings to other cell types by measuring HyPer reporter fluorescence ratios in hypoxic in SH-SY5Y and Hep3B human hepatocellular carcinoma cells. Ratiometric imaging of both cell types showed no change in peroxide levels following $2 \mathrm{~h}$ of hypoxia, which was sufficient time to activate HIF1a-dependent gene expression. This absence of changes in peroxide levels during hypoxia could not be attributed to a lack of HyPer reporter responsiveness to peroxide in these cell types, since complex IV inhibition (KCN) (Figure S1C) or addition of exogenous peroxide (Figure S1G) following the hypoxic exposure led to the expected significant increases in reporter activity. Together with our antioxidant protein expression results, these data suggest that mitochondrial peroxide either decreases or is unchanged by hypoxia in primary (pancreatic beta islets) and transformed cell types (SH-SY5Y, Hep3B).

\section{HIF1a stabilisation is not oxidant initiated in hypoxia}

We studied the regulation of HIF1a protein stabilisation in hypoxia directly by first establishing the sensitivity and dynamic range of HIF-luciferase reporter protein levels. The HIF-luciferase reporter contains the oxygen-dependent domain (ODD) of HIF1a fused to luciferase (ODD-luciferase). Prior studies from one of our groups have demonstrated that this reporter behaves like endogenous HIF but does not influence endogenous HIF activity (Karuppagounder et al., 2013; Smirnova et al., 2010). Treatment with deferoxamine (DFO), a canonical HIF PHD inhibitor, allowed dynamic monitoring of the HIF reporter protein levels across a wide range of DFO concentrations (Figure $2 \mathrm{~A}$ and 
2B). As an independent measure, we also assayed the activity of the HIF1a-luciferase reporter by measuring luciferase activity. These assays showed that the HIF1a-luciferase reporter measured by photometric luciferase activity possesses a high dynamic range and low coefficient of variation (Figure 2C). Indeed, the changes in HIF1a-luciferase activity measurements with increasing doses of DFO showed a strong correlation with the quantitative changes in HIF1 $\alpha$-luciferase reporter protein levels measured by quantitative immunoblotting (Figure 2D).

Previous studies have shown that decreasing ROS by forced expression of individual antioxidant enzymes can decrease HIF1a protein levels (Brunelle et al., 2005; Chandel et al., 2000). We confirmed these findings with our HIF1a-luciferase reporter by forcing the expression of either catalase (a peroxide scavenger), GPX1 (a peroxide scavenger) or MnSOD (a superoxide scavenger and peroxide generator) (Figure 2E). SHSY5Y cells expressing ODD-Luc were transduced with individual antioxidant enzymes encoded in distinct adenoviral constructs or an adenovirus encoding GFP only as a protein control. At $72 \mathrm{~h}$ following infection, GFP expression was observed in nearly $90 \%$ of SH-SY5Y cells (Figures S2A and S2B). Accordingly, the cells were tested for specific enzyme activities of MnSOD, catalase or GPX1. These studies showed a sevenfold, elevenfold and threefold increase in specific activity over GFP controls for MnSOD-, catalase- and GPX1-expressing cells, respectively (Figures 2F, 2G and $2 \mathrm{H}$ ).

Upon verifying the increases in individual antioxidant enzyme activities (MnSOD, GPX1 and catalase) that can either increase (MnSOD) or decrease peroxide (GPX1, catalase), we then examined the effect of these manipulations on HIF1 $\alpha$ stability. The mitochondrial peroxide model of HIF regulation predicts that MnSOD should increase 
HIF1 $\alpha$ stability in hypoxia, whereas GPX1 and catalase should diminish HIF1 $\alpha$ stability. In contrast to these predictions, we found that MnSOD had no effect on HIF1 $\alpha$ reporter activity, whereas catalase increased reporter activity and GPX1 decreased it (Figure 3A). We further verified that our HIF1a luciferase reporter accurately reflected endogenous HIF1a levels by performing quantitative fluorescence immunoblotting. These assays showed that the changes in endogenous HIF1 $\alpha$ protein are similar to those identified with the HIF1 $\alpha$ reporter (Figure 3B). From these findings, we concluded that HIF1 $\alpha$ levels are not correlated with mitochondrial peroxide production.

Since catalase is a peroxisomal enzyme and GPX1 localises to the cytosol and mitochondria, our results could not formally exclude the possibility that GPX1 localisation to the mitochondria allowed it to reduce HIF1a levels, while the inability of catalase to penetrate this compartment did not allow it to reduce HIF1a levels. We addressed this possibility by forced expression of PRDX3, a member of the peroxiredoxin family of antioxidant enzymes that function as thioredoxin-dependent peroxide reductases in the mitochondria. Contrary to the GPX1 effects, forced expression of PRDX3 increased the levels of HIF1 $\alpha$ during hypoxia, as measured by either HIF1 $\alpha$ reporter activity (Figure 3C) or quantitative fluorescence immunoblotting (Figure 3D). We also confirmed these findings in primary neurons (Figures $3 \mathrm{E}$ and $3 \mathrm{~F}$ ), where adenoviral constructs also effectively increased expression of the antioxidant enzymes (Figures S2C and S2D). As a final test to confirm a reduction in oxidant production by GPX1, PRDX3 or catalase in SH-SY5Y cells, we measured the fluorescence of 5,6-carboxydichlorofluorescein (a nonselective redox sensitive reporter) using flow cytometry. These experiments confirmed the ability of GPX1, PRDX3 and catalase to reduce steady-state DCF oxidation, 
presumably resulting from oxidants generated physiologically (Figures S3A and S3B). However, no significant change was observed in the peroxide level in response to MnSOD expression, despite a significant increase in the MnSOD enzyme activity and protein level. This was unexpected and could reflect a compensatory activation of other antioxidants, such as GPX1, GPX4 or Prdx3, in response to increased MnSOD activity. We verified that DCF loading and the corresponding antioxidant effects were not different from normoxic or hypoxic cells, thereby arguing against the possibility that our redox reporter or the antioxidant enzymes are behaving differently in normoxia and hypoxia (Figures S3D and S3E).

Our findings did not exclude the possibility that antioxidants alter HIF1a protein levels by differential regulation of either Hif mRNA synthesis or Hif mRNA stability. Accordingly, we monitored Hif1a mRNA levels in the cells overexpressing catalase, GPX1 and PRDX3. Quantitative PCR revealed that Hif mRNA levels were not changed in a manner that would contradict the observed ROS-independent changes in HIF1a stability (Figures 4A and 4B). We confirmed that the changes observed in HIF1a protein stability are related to changes in its half-life by examining the stability of HIF1a protein in the presence of cycloheximide, which suppresses de novo protein synthesis in cells pretreated either with or without MG132. As expected, we found that catalase and PRDX3, which increase HIF1a protein levels, also increased the HIF1a half-life (Figures 4C, 4D and 4E). By contrast, GPX1, which diminished HIF1 $\alpha$ protein levels, decreased the HIF1 $\alpha$ half-life (Figure 4D). Moreover, MG132 treatment significantly enhanced the Hif-1a halflife in all cases, showing that the antioxidant-led changes in hypoxic Hif-1a stabilisation were a result of alterations in proteasomal degradation. 
We then examined whether our findings in primary neurons and neuroblastoma cells could be extended to non-neural cell types by examining the ability of antioxidant enzymes capable of modulating peroxide levels to modulate HIF1a stability in hypoxic Hep3B hepatocarcinoma cells and hypoxic HeLa cervical cancer cells. Forced expression of catalase, GPX1 or PRDX3 using adenoviral vectors significantly increased the protein levels of each of the antioxidant enzymes in Hep3B or HeLa cells (Figures S4 and S5). Similar to the effects in primary neurons or neuroblastoma cells, we did not observe a uniform reduction in HIF1a stability during hypoxia by forced expression of enzymes whose common activity is to reduce peroxide in these non-neural cell types (Figures S4 and S5). Taken together, our findings suggest that peroxide levels are uncoupled from HIF1 $\alpha$ stability in both neural and non-neural cells.

\section{Is Factor Inhibiting HIF a target for ROS in hypoxia?}

Previous studies have highlighted the role that Factor Inhibiting HIF (FIH) in the redox regulation of HIF1a. FIH inhibits HIF-dependent transcription by hydroxylating an asparagine in the C-terminal domain of the HIF1a protein that would normally interact with the co-activator CBP during hypoxia (Ema et al., 1999; Lando et al., 2002; Sang, Fang, Srinivas, Leshchinsky, \& Caro, 2002). Suppression of FIH should, therefore, facilitate CBP recruitment and enhance HIF1 $\alpha$ target gene transcription. We determined whether a change in HIF-dependent transcription correlated with changes in HIF1 $\alpha$ protein levels by examining Enolase2 and Bnip3 mRNA expression levels, as these are two established HIF1a target genes (Aminova et al., 2005; Poitz et al., 2014) in neuroblastoma SH-SY5Y cells and primary cortical neurons (PCNs). As expected, changes in Enolase2 and Bnip3 mRNA levels correlated with the HIF1a luciferase 
reporter levels (Figures 5A-5F). These results suggest that the differential regulation derives from differential effects of antioxidant enzymes on HIF1 a protein stability, rather than on $\mathrm{FIH}$.

\section{Neither Reactive Oxygen Species nor Reactive Lipid Species regulate HIF-1a stability in hypoxia}

Recent compelling evidence has shown that reactive lipid species (RLS) are sufficient to drive HIF-dependent transcription via their effects on FIH inhibition without affecting HIF1a stability (Masson et al., 2012). Accordingly, we forced expression of GPX4, a selenoprotein that neutralises RLS (Figure 6A). We manipulated steady-state levels using the GPX4 protein fused to an optimised destabilisation domain (dd) from the prokaryotic dihydrofolate reductase gene. The dd domain destabilises GPX4 protein unless trimethoprim (TMP, $10 \mu \mathrm{M}$ ) is present (Figure 6B). TMP enhanced the GPX4 levels in neuroblastoma cells expressing ddGPX4, but increasing GPX4 levels had no effect on the hypoxia-induced HIF1 a stability (Figures 6C-6D) or on HIF1a-dependent transcription (Figures 6E and 6F). We verified that GPX4 diminished RLS (Figure S3C) and neutralised the ferroptosis induced by glutamate, a form of cell death mediated by reactive lipid species that is abrogated by GPX4 (Figures 6G and 6H) (Tan, Wood, \& Maher, 1998). Taken together, these findings argue against a central role for hydrogen peroxide or for lipid peroxides in mediating HIF1 a stabilisation during hypoxia.

\section{Discussion}


Seminal studies have supported the notion that mitochondria are essential regulators of hypoxic adaptation and that they possibly act via their ability to generate peroxide (Agani et al., 2000; Chandel et al., 1998). In this paper, we show that the HIF1a stability mediated by HIF PHDs during hypoxia does not require peroxide. These data include our inability to detect an increase in peroxide during hypoxia (Figure $1 \mathrm{~L}$ ), the lack of homeostatic changes in antioxidant protein expression during hypoxia (Figures 1B-1I) and the failure of forced expression of antioxidant enzymes (catalase, GPX1, and PRDX3) that share a common ability to diminish cellular peroxide to influence HIF1a stability and transcription in the same direction (Figures 3 and 5). Our findings agree with prior studies that showed: 1) that HIF PHDs are not inhibited by exogenously added peroxide (Chua et al., 2010), and 2) that forced expression of an alternative oxidase which directly transfers electrons from coenzyme $Q$ to oxygen to form water maintains HIF1 $\alpha$ stability in hypoxia, despite reducing superoxide generation at Complex III (Chua et al., 2010).

Our results cannot be attributed to differences in mitochondrial ROS generation by transformed versus primary cells, or to differences in neuron-like versus non-neural cells, as SH-SY5Y neuroblastoma cells and primary cortical neurons showed similar effects, as did Hep3B hepatocellular carcinoma cells and HeLa cervical cancer cells. While we cannot exclude the possibility that culture conditions, such as serum lots, could reconcile our results with prior studies, in aggregate, the findings favour a role for mitochondria in modulating HIF1a stability via their effects as oxygen consumers rather than as peroxide second messenger generators.

\section{Peroxide scavengers have distinct effects on hypoxic HIF1 $\alpha$ stability}


Prior studies have shown that, in some cell types, ROS generation in hypoxia could be related to increased oxidant production or decreased defences (Naranjo-Suarez et al., 2012). We addressed the possibility that the imbalance of oxidants and antioxidants plays a regulatory role in mediating hypoxia signalling by the forced expression of distinct antioxidant enzymes known to either reduce (GPX1, catalase and PRDX3) or enhance (MnSOD) peroxide levels. Despite evidence for increased activity of the antioxidant enzymes studied using multiple experimental approaches, we found that HIF1 $\alpha$ stability and transcription did not correlate with the effects on peroxide levels. Indeed, MnSOD had no effect on HIF1a stability, GPX1 diminished HIF1 $\alpha$ stability and catalase and PRDX3 increased HIF1 $\alpha$ stability in neuroblastoma cells and primary neurons (Figures 3A-3D). Similar uncoupling was observed in non-neural cell types as well (Figures S4 and S5). These results uncouple peroxide generation in the mitochondria from HIF1 $\alpha$ stability via the HIF PHDs. One likely explanation is that the GPX1, catalase, and PRDX3 influenced HIF1 $\alpha$ stability either via indirect but distinct effects on oxygen consumption or, alternatively, by differential but direct effects on proteins that influence HIF1 $\alpha$ regulation.

\section{HIF1a stability under hypoxia is not regulated by reactive lipid species (RLS)}

Recent studies have highlighted a potential role for RLS in regulating HIF transcription rather than HIF1 $\alpha$ stability. Accordingly, we forced the expression of GPX4, a selenoprotein with known ability to neutralise reactive lipid species. Despite being active in combating RLS-mediated ferroptotic death in transformed cells (Figure 6H), GPX4 had no effect on HIF1a stability during hypoxia (Figures 6C and 6D) or on HIF-dependent transcription (Figures 6E and 6F). These data suggest that while some RLS (e.g. tert- 
butyl hydroperoxide) are sufficient to activate HIF transcription, they are not necessary for stabilisation of HIF1a or for driving HIF1a-dependent transcription during hypoxia.

Our collective data show that ROS or RLS are dispensable for HIF stability. The studies support a focus on HIF prolyl hydroxylase inhibition as a strategy for augmenting or increasing HIF activation in a host of disease states, including chronic kidney failure (to augment Epo), stroke and heart attack (Bryant et al., 2016; Conde et al., 2012; Semenza, 2012, 2014; Sheldon et al., 2014; Weidemann et al., 2008).

\section{Methods}

Cell lines and In Vitro Tissue Culture Studies

Immature primary cortical neurons were isolated from CD1 mice embryos (embryonic day 15 [E15]) as previously described (Ratan, Murphy, \& Baraban, 1994) by following the protocol approved by IACUC at Weill Cornell Medicine. SH-SY5Y human neuroblastoma cells (purchased from ATCC) were cultured in DMEM/F-12 plus GlutaMAX medium added with $10 \%$ foetal bovine serum (Invitrogen) and 1\% penicillin/streptomycin (Invitrogen). HeLa cells and Hep3B cells (purchased from ATCC) were cultured in EMEM medium added with $10 \%$ foetal bovine serum (Invitrogen) and 1\% penicillin/streptomycin (Invitrogen).

Islets were harvested from Sprague-Dawley male rats ( 250g, Envigo, Huntingdon, Cambridgeshire, United Kingdom) anesthetised by an intraperitoneal injection of sodium pentobarbital (35 $\mathrm{mg} / 230 \mathrm{~g}$ rat). All procedures were approved by the University of Washington Institutional Animal Care and Use Committee. Islets were prepared and purified as previously described (Sweet et al., 2004) and then cultured at 
$37^{\circ} \mathrm{C}$ in RPMI Media 1640 (Gibco, Grand Island, NY) supplemented with $10 \%$ heatinactivated foetal bovine serum (Atlanta Biologicals, Lawrenceville, GA) for specified times with the adenovirus coding the $\mathrm{H}_{2} \mathrm{O}_{2}$-sensitive dye HyPer.

Adenoviral transduction and hypoxia/normoxia exposure

Adenoviral constructs of MnSOD, catalase GPX1 and respective GFP controls were purchased from the University of lowa, Viral Vector Core Facility. Adenoviral constructs of ddGPX4 (GPX4 with destabilisation domain) and the respective GFP control were obtained from ViraQuest, Inc. (North Liberty, IA) and adenoviral constructs of PRDX3, GRX1 and the respective GFP controls were obtained from Vector Biolabs. For the GPX4 construct, we leveraged a novel technique recently developed by the Wandless group (Iwamoto, Bjorklund, Lundberg, Kirik, \& Wandless, 2010) for deliberately regulating the level of expression of a protein of interest. An adenoviral construct of ddGPX4 had an E. coli dihydrofolate reductase (ecDHFR) mutant (called a degradation domain) fused to its CMV promoter which displays trimethoprim (TMP)-dependent stability. Because of the fusion of the degradation domain to the GPX4 promoter, GPX4 also displayed TMPdependent stability. Without TMP, GPX4 was rapidly degraded completely through the proteasome, but increasing doses of TMP increased the GPX4 stability. Treatment of ddGPX4-expressing cells with $10 \mu \mathrm{M}$ TMP for $12 \mathrm{~h}$ stabilised ddGPX4 very well. SHSY5Y, HeLa or Hep3B cells were transduced with different adenoviral constructs at 500 MOI (multiplicity of infection) and incubated for $72 \mathrm{~h}$; primary immature cortical neurons (PCNs) were transduced with different adenoviral constructs at $100 \mathrm{MOI}$ (Multiplicity of infection) for $48 \mathrm{~h}$. The maximal expression of these constructs was determined by expressing the adenoviral construct of GFP at $500 \mathrm{MOI}$ for $72 \mathrm{~h}$ in SH-SY5Y cells and 
$100 \mathrm{MOI}$ for $48 \mathrm{~h}$ in PCNs on slides and staining them with GFP antibody (Abcam, ab6556). After $60 \mathrm{~h}$ of incubation, $10 \mu \mathrm{M}$ TMP was added to ddGPX4 expressing cells and their respective control GFP expressing cells and the cells were incubated for a further $12 \mathrm{~h}$ to get stabilised GPX4 expression. Parallel sets without transduction of adenoviral constructs but probed with the same GFP antibody were used as negative controls in each in vitro model (Figure S2). Thereafter, one set was kept under normoxia ( $21 \%$ oxygen) and a parallel set under hypoxia (1\% oxygen) for $4 \mathrm{~h}$. The changes in endogenous antioxidants were studied by exposing SH-SY5Y cells and primary cortical neurons to normoxia/hypoxia for a relatively longer duration of $8 \mathrm{~h}$ to allow visualisation of a clearer difference under normoxic and hypoxic conditions.

Real-time changes in hydrogen peroxide during hypoxia were studied using an adenovirus containing the cytosolic $\mathrm{H}_{2} \mathrm{O}_{2}$ sensor, pHyPer-cyto vector (FP942, Evrogen, Moscow, Russia) (Belousov et al., 2006) generated by Vector Biolabs (Malvern, PA), as previously described (Karamanlidis et al., 2013). The $\mathrm{H}_{2} \mathrm{O}_{2}$ sensor was transduced into intact islets during incubation in RPMI media supplemented with $10 \%$ heat-inactivated foetal bovine serum and the adenoviruses at $100 \mathrm{MOI}$ for 3 days at $37^{\circ} \mathrm{C}$, as previously optimised (Neal et al., 2016). SH-SY5Y cells and Hep3B cells were also transduced with the $\mathrm{H}_{2} \mathrm{O}_{2}$ sensor at $100 \mathrm{MOI}$ in a similar manner.

$\underline{\text { Real-time epifluorescence imaging of intracellular } \mathrm{H}_{2} \mathrm{O}_{2}}$

Real-time imaging experiments were carried out while islets were perifused using a commercially available temperature-controlled Bioptechs FCS2, which is a closed system, parallel plate flow chamber (Butler, PA) as previously described (Neal et al., 2016). After the islets were loaded into the perfusion chambers, the chamber was sealed 
and mounted onto the stage of a Nikon Eclipse TE-200 inverted microscope. KRB was pumped through the perifusion chamber at flow rates of $120 \mu \mathrm{L} /$ min using a Masterflex L/S peristaltic pump (Cole-Parmer, Vernon Hills, IL). Use of an artificial gas exchanger positioned on the inflow side of the perifusion chamber enabled rapid changes in the concentrations of dissolved oxygen by switching the source gas tank between tanks containing $21 \%$ and $1 \%$ oxygen (balance $5 \%$ carbon dioxide and nitrogen)(Sweet, Cook, et al., 2002; Sweet, Khalil, et al., 2002). The HyPer signal was generated by dual fluorescence excitation with a xenon arc lamp (Lambda LS-1620, Sutter Instrument Company, Novato, CA) through either a $405 / 30 \mathrm{~nm}$ or a $480 / 40 \mathrm{~nm}$ bandpass filter and detected at $510 \mathrm{~nm}$ through a long-pass dichroic mirror with a cutoff below $500 \mathrm{~nm}$. The images were taken using a digital camera (Photometrics Cool Snap HQ2 CCD camera, Tucson, AZ) through a 40X Super Fluor Nikon objective (DIC H/N2). Data were expressed ratiometrically, where the excitation intensities at $480 \mathrm{~nm}$ were divided by those obtained during excitation at $405 \mathrm{~nm}$. A similar procedure was used for real time monitoring of $\mathrm{H}_{2} \mathrm{O}_{2}$ in SH-SY5Y cells and Hep3B cells. We further confirmed the specificity of the HyPer signals by treating Hep3B cells with bacterial Streptolysin-O (which creates pores in the cell membranes) to selectively permeabilise the plasma membrane, followed by exposure to increasing concentrations of exogenous $\mathrm{H}_{2} \mathrm{O}_{2}$. Real time measurement of changes in the HyPer signals in response to exogenous addition of $\mathrm{H}_{2} \mathrm{O}_{2}$ confirmed the specificity of the HyPer signal with regard to $\mathrm{H}_{2} \mathrm{O}_{2}$.

$\underline{\text { Real-time epifluorescence imaging of intracellular NAD }(P) H}$

$\mathrm{NAD}(\mathrm{P}) \mathrm{H}$ autofluorescence was measured similarly to $\mathrm{H}_{2} \mathrm{O}_{2}$, except no dye loading was required and the excitation and emission wavelengths were 360 and $460 \mathrm{~nm}$, 
respectively, as previously described (Gilbert, Jung, Reed, \& Sweet, 2008). We calibrated the relative fluorescence units (RFU) at the end of experiments by measuring the steady state RFU in the presence of potassium cyanide (KCN) and, subsequently, FCCP. The normalised fluorescence of $\mathrm{NAD}(\mathrm{P}) \mathrm{H}$ was then calculated as follows:

$\%$ Reduced NAD $(\mathrm{P}) \mathrm{H}=100$ * $\left(\mathrm{RFU}_{\text {test }}-\mathrm{RFU}_{\mathrm{FCCP}}\right) /\left(\mathrm{RFU}_{K C N}-\mathrm{RFU}_{\mathrm{FCCP}}\right)$ (Eq. 1)

where RFU $\mathrm{FCCP}_{\text {and }}$ RFUKCN equals the average of the final 10 time points during which each agent was present.

$\underline{\text { Real-time measurement of insulin secretion rate }}$

Outflow fractions from the flow system containing islets were collected in a fraction collector for subsequent measurement of insulin, as described previously (Sweet et al., 2004; Sweet, Cook, et al., 2002; Sweet, Khalil, et al., 2002). The insulin secretion rate was calculated as the flow rate $(80 \mu \mathrm{L} / \mathrm{min})$ times the insulin concentration in the outflow fractions, over the number of islets in the chamber, which was typically 50 (Sweet \& Gilbert, 2006). Insulin was measured by radioimmunoassay (RI-13K, EMD Millipore, Darmstadt, Germany) as per the manufacturer's instructions.

ODD-luciferase activity assay

The ODD-luciferase construct with the pcDNA3.1 plasmid vector was constructed as previously described (Safran et al., 2006). The proline p402 and p564 present within the oxygen degradation domain (ODD) of HIF1a, when hydroxylated by HIF-PHDs, allow its binding to the VHL protein that targets it for proteasomal degradation. In this way, the stabilisation of ODD can be used as a marker of HIF1a stability (Safran et al., 2006; Smirnova et al., 2010). Because of the luciferase tagged with ODD, the increase in ODD stability leads to a proportional increase in the luciferase activity and this provides a very 
good way of measuring the HIF $1 \alpha$ stability in a quantitative manner with a wide dynamic range. To this end, we used SH-SY5Y cells stably expressing ODD-luciferase. These cells were made by co-transfecting ODD-luciferase plasmid along with a puromycin resistance plasmid in SH-SY5Y cells, and stably transfected cells were positively selected in the presence of $4 \mu \mathrm{g} / \mathrm{mL}$ puromycin. Luciferase activity was measured by luciferase assay kit (Promega) using an LMaxII ${ }^{\mathrm{TM}}$ microplate luminometer (Molecular Devices). ODD-luciferase activity was normalised to the protein content of each well measured by Bio-Rad DC ${ }^{\mathrm{TM}}$ protein assay kit.

\section{Gene expression study}

Total RNA was prepared from SH-SY5Y cells using the Nucleospin RNA kit (MachereyNagel) and following their protocol. Real time PCRs were performed as a duplex reaction using FAM labelled Enolase2 (Human - Hs00157360_m1), Bnip3 (Human Hs00969291_m1), and Hif1a (Human - Hs00153153_m1) gene expression assays (Thermo Fisher Scientific) and VIC labelled human $\beta$ actin endogenous control probe (Human - 4326315E) or RNA28S5 (Human - Hs03654441_s1) (Thermo Fisher Scientific) so that amplified mRNA can be normalised to $\beta$ actin or RNA28S5. These experiments were performed using a 7500 Real-time PCR system (Applied Biosystems) using standard PCR protocols and amplification conditions.

We measure gene expression in pancreatic islets exposed to normoxia or hypoxia by first placing the islets in incubators containing either $21 \%$ or $1 \%$ oxygen for $2 \mathrm{~h}$. The islets were then lysed and total RNA was purified using the RNeasy Mini Kit (Qiagen, Hilden Germany). Bnip3, Kdm6b and rat Actin B mRNA were measured by quantitative PCR using FAM labelled Bnip3 (Rat - Rn00821446_g1), Kdm6b (Rat - Rn01471506_m1) 
gene expression assays and VIC labelled rat $\beta$ actin endogenous control probe (Rat 4352340E), all purchased from Thermo Fisher Scientific. These experiments were performed on an Mx3005P® Multiplex QPCR System (Stratagene, La Jolla, CA) with samples loaded in triplicate using 100ng of total RNA.

\section{Enzyme activity assays}

For GPX1, catalase and MnSOD activity assays, cells in each sample expressing the relevant adenoviral constructs were collected, lysed and used for respective enzyme activity assays following the protocols of GPX1, catalase and SOD assay kits from Biovision. Total protein was measured using the Bio-Rad DC protein assay kit. The enzyme activity was normalised to the protein concentration for each sample.

\section{Cell viability assay}

In order to test the functional activity of GPX4, immature primary cortical neurons (E15) were isolated from mouse embryos and plated at $10^{6}$ cells $/ \mathrm{mL}$ in a 96 -well plate. The next day, cells were transduced with GPX4 adenoviral constructs at $100 \mathrm{MOI}$. After a $24 \mathrm{~h}$ incubation, the cells were treated with the glutamate analogue, homocysteic acid (HCA) (5 mM), which inhibits the $\mathrm{Xc}^{-}$transporter, thereby inhibiting cysteine uptake and leading to glutathione depletion and an increase in intracellular oxidative stress. Cells were also treated with $10 \mu \mathrm{M}$ TMP at the same time to stabilise the GPX4 protein. The next day, cell viability was assessed by the MTT assay (Promega) to evaluate whether ddGPX4 is functionally active and shows its protective effect by decreasing oxidant levels under oxidative stress.

ROS measurement through DCF flow cytometry 
We measured changes in ROS levels using the molecular probe DCFDA (2',7'-dichlorofluorescein diacetate). SH-SY5Y cells in normoxia as well as hypoxia were loaded with $20 \mu \mathrm{M}$ DCFDA for $30 \mathrm{~min}$. DCFDA diffuses through the cell membrane and is deacetylated by intracellular esterases to a non-fluorescent form, which is later oxidised by ROS into the highly fluorescent 2',7'- dichlorofluorescein (DCF). Thereafter, parallel sets of cells in normoxia as well as hypoxia were treated with $5 \mathrm{mM} \mathrm{H}_{2} \mathrm{O}_{2}$ for 30 min as positive controls. After incubation, fluorescence was measured by flow cytometry at the wavelengths of excitation at $485 \mathrm{~nm}$ and emission at $535 \mathrm{~nm}$. The production of ROS was measured as the mean fluorescence index multiplied by the respective cell counts and expressed as fold change with respect to the control.

$\underline{\text { Immunoblotting }}$

Protein extracts were prepared using 1\% Triton buffer containing protease inhibitor, separated by SDS-PAGE, transferred onto nitrocellulose membranes and probed with antibodies against GFP (Cell Signaling Technology; 2555), MnSOD (Sigma-Aldrich; HPA001814), catalase (Sigma-Aldrich; C0979), GPX1 (Cell Signaling Technology; 3286S and Novus Biologicals; NBP1-33620), GPX4 (LSBio; LS B1596), PRDX3 (Novus Biologicals; NBP2-19777), Luciferase (Santa Cruz Biotechnology; sc-74548), HIF1a (Novus Biologicals; NB100-479) and citrate synthase (Cell Signaling Technology; 14309S).

\section{Quantification and Statistical Analysis}

All experiments were performed as at least three independent sets, and data were displayed as means \pm standard deviation (SD). Statistical significance was assessed in GraphPad Prism using either Student's t test to compare values between two specific 
groups, one-way ANOVA followed by Dunnett's post-hoc test/Tukey's Post-hoc test to compare the values of more than two groups or two-way ANOVA followed by Bonferroni's post-hoc test to compare the values of two groups under two different conditions at a given time. Statistical details for each figure can be found in their respective figure legends. The $p$ value of 0.05 or less was considered statistically significant in all statistical analyses.

\section{Online Supplemental material}

Fig.S1 provides additional evidence in SH-SY5Y cells or Hep3B cells that hypoxia does not increase peroxide levels. Fig. S2 shows a validation of the degree of expression of transduced transgenes encoded within adenoviral vectors in SH-SY5Y cell and primary cortical neurons (PCNs) using adenoviral particles encoding GFP. Fig. S3 shows the validation of the functional activity of antioxidants to reduce reactive oxygen species. Fig. S4 provides additional evidence in HELA cells that the stabilisation of HIF1a is not oxidant-initiated in hypoxia. Fig. S5 provides another additional evidence in Hep3B cells that the stabilisation of HIF $1 \alpha$ is not oxidant-initiated in hypoxia.

\section{Acknowledgements}

This work was supported by the National Institute of Health (Grant P01 AG14930-15A1, Project 1 to RRR), by a Dr. Miriam and Sheldon G. Adelson Medical Research Foundation grant to RRR, by a Goldsmith Fellowship to Amit Kumar for transition to independence, and by Diabetes Research Center Cell Function Analysis Core funding (P30 DK17047; University of Washington) to lan Sweet. We also thank Sunghee Cho and Jiwon Yang for their help in data acquisition through flow cytometry. We also acknowledge the critical 
comments and suggestions from Drs. Ratcliffe, Schofield, Semenza, Silva and Ciechanover.

\section{Competing interests}

The authors declare no competing financial interests.

\section{References}

Agani, F. H., Pichiule, P., Chavez, J. C., \& LaManna, J. C. (2000). The role of mitochondria in the regulation of hypoxia-inducible factor 1 expression during hypoxia. J Biol Chem, 275(46), 35863-35867. doi: 10.1074/jbc.M005643200

Aminova, L. R., Chavez, J. C., Lee, J., Ryu, H., Kung, A., Lamanna, J. C., \& Ratan, R. R. (2005). Prosurvival and prodeath effects of hypoxia-inducible factor-1alpha stabilization in a murine hippocampal cell line. J Biol Chem, 280(5), 3996-4003. doi: 10.1074/jbc.M409223200

Aminova, L. R., Siddiq, A., \& Ratan, R. R. (2008). Antioxidants, HIF prolyl hydroxylase inhibitors or short interfering RNAs to BNIP3 or PUMA, can prevent prodeath effects of the transcriptional activator, HIF-1alpha, in a mouse hippocampal neuronal line. Antioxid Redox Signal, 10(12), 1989-1998. doi: 10.1089/ars.2008.2039

Bae, Y. S., Kang, S. W., Seo, M. S., Baines, I. C., Tekle, E., Chock, P. B., \& Rhee, S. G. (1997). Epidermal growth factor (EGF)-induced generation of hydrogen peroxide. Role in EGF receptor-mediated tyrosine phosphorylation. J Biol Chem, 272(1), 217-221. 
Bell, E. L., Klimova, T. A., Eisenbart, J., Moraes, C. T., Murphy, M. P., Budinger, G. R., \& Chandel, N. S. (2007). The Qo site of the mitochondrial complex III is required for the transduction of hypoxic signaling via reactive oxygen species production. $J$ Cell Biol, 177(6), 1029-1036. doi: 10.1083/jcb.200609074

Belousov, V. V., Fradkov, A. F., Lukyanov, K. A., Staroverov, D. B., Shakhbazov, K. S., Terskikh, A. V., \& Lukyanov, S. (2006). Genetically encoded fluorescent indicator for intracellular hydrogen peroxide. Nat Methods, 3(4), 281-286. doi: $10.1038 /$ nmeth 866

Brunelle, J. K., Bell, E. L., Quesada, N. M., Vercauteren, K., Tiranti, V., Zeviani, M., . . . Chandel, N. S. (2005). Oxygen sensing requires mitochondrial ROS but not oxidative phosphorylation. Cell Metab, 1(6), 409-414. doi: 10.1016/j.cmet.2005.05.002

Bryant, A. J., Carrick, R. P., McConaha, M. E., Jones, B. R., Shay, S. D., Moore, C. S., . . Lawson, W. E. (2016). Endothelial HIF signaling regulates pulmonary fibrosisassociated pulmonary hypertension. Am J Physiol Lung Cell Mol Physiol, 310(3), L249-262. doi: 10.1152/ajplung.00258.2015

Chandel, N. S., Maltepe, E., Goldwasser, E., Mathieu, C. E., Simon, M. C., \& Schumacker, P. T. (1998). Mitochondrial reactive oxygen species trigger hypoxiainduced transcription. Proc Natl Acad Sci U S A, 95(20), 11715-11720.

Chandel, N. S., McClintock, D. S., Feliciano, C. E., Wood, T. M., Melendez, J. A., Rodriguez, A. M., \& Schumacker, P. T. (2000). Reactive oxygen species generated at mitochondrial complex III stabilize hypoxia-inducible factor-1alpha during 
hypoxia: a mechanism of $\mathrm{O} 2$ sensing. J Biol Chem, 275(33), 25130-25138. doi: 10.1074/jbc.M001914200

Choudhry, H., \& Harris, A. L. (2018). Advances in Hypoxia-Inducible Factor Biology. Cell Metab, 27(2), 281-298. doi: 10.1016/j.cmet.2017.10.005

Christman, M. F., Storz, G., \& Ames, B. N. (1989). OxyR, a positive regulator of hydrogen peroxide-inducible genes in Escherichia coli and Salmonella typhimurium, is homologous to a family of bacterial regulatory proteins. Proc Natl Acad Sci U S A, 86(10), 3484-3488.

Chua, Y. L., Dufour, E., Dassa, E. P., Rustin, P., Jacobs, H. T., Taylor, C. T., \& Hagen, T. (2010). Stabilization of hypoxia-inducible factor-1alpha protein in hypoxia occurs independently of mitochondrial reactive oxygen species production. J Biol Chem, 285(41), 31277-31284. doi: 10.1074/jbc.M110.158485

Conde, E., Alegre, L., Blanco-Sanchez, I., Saenz-Morales, D., Aguado-Fraile, E., Ponte, B., . . Garcia-Bermejo, M. L. (2012). Hypoxia inducible factor 1-alpha (HIF-1 alpha) is induced during reperfusion after renal ischemia and is critical for proximal tubule cell survival. PLoS One, 7(3), e33258. doi: 10.1371/journal.pone.0033258

Doege, K., Heine, S., Jensen, I., Jelkmann, W., \& Metzen, E. (2005). Inhibition of mitochondrial respiration elevates oxygen concentration but leaves regulation of hypoxia-inducible factor (HIF) intact. Blood, 106(7), 2311-2317. doi: 10.1182/blood-2005-03-1138

Ema, M., Hirota, K., Mimura, J., Abe, H., Yodoi, J., Sogawa, K., . . Fujii-Kuriyama, Y. (1999). Molecular mechanisms of transcription activation by HLF and HIF1alpha 
in response to hypoxia: their stabilization and redox signal-induced interaction with CBP/p300. EMBO J, 18(7), 1905-1914. doi: 10.1093/emboj/18.7.1905

Emerling, B. M., Platanias, L. C., Black, E., Nebreda, A. R., Davis, R. J., \& Chandel, N. S. (2005). Mitochondrial reactive oxygen species activation of p38 mitogenactivated protein kinase is required for hypoxia signaling. Mol Cell Biol, 25(12), 4853-4862. doi: 10.1128/MCB.25.12.4853-4862.2005

Epstein, A. C., Gleadle, J. M., McNeill, L. A., Hewitson, K. S., O'Rourke, J., Mole, D. R., . . Ratcliffe, P. J. (2001). C. elegans EGL-9 and mammalian homologs define a family of dioxygenases that regulate HIF by prolyl hydroxylation. Cell, 107(1), 4354.

Gilbert, M., Jung, S. R., Reed, B. J., \& Sweet, I. R. (2008). Islet oxygen consumption and insulin secretion tightly coupled to calcium derived from L-type calcium channels but not from the endoplasmic reticulum. J Biol Chem, 283(36), 24334-24342. doi: 10.1074/jbc.M802097200

Hagen, T., Taylor, C. T., Lam, F., \& Moncada, S. (2003). Redistribution of intracellular oxygen in hypoxia by nitric oxide: effect on HIF1alpha. Science, 302(5652), 19751978. doi: $10.1126 /$ science. 1088805

Hameed, L. S., Berg, D. A., Belnoue, L., Jensen, L. D., Cao, Y., \& Simon, A. (2015). Environmental changes in oxygen tension reveal ROS-dependent neurogenesis and regeneration in the adult newt brain. Elife, 4. doi: 10.7554/eLife.08422

Ivan, M., Haberberger, T., Gervasi, D. C., Michelson, K. S., Gunzler, V., Kondo, K., . . . Kaelin, W. G., Jr. (2002). Biochemical purification and pharmacological inhibition 
of a mammalian prolyl hydroxylase acting on hypoxia-inducible factor. Proc Natl Acad Sci U S A, 99(21), 13459-13464. doi: 10.1073/pnas.192342099

Ivan, M., Kondo, K., Yang, H., Kim, W., Valiando, J., Ohh, M., ... Kaelin, W. G., Jr. (2001). HIFalpha targeted for VHL-mediated destruction by proline hydroxylation: implications for $\mathrm{O} 2$ sensing. Science, 292(5516), 464-468. doi: 10.1126/science. 1059817

Iwamoto, M., Bjorklund, T., Lundberg, C., Kirik, D., \& Wandless, T. J. (2010). A general chemical method to regulate protein stability in the mammalian central nervous system. Chem Biol, 17(9), 981-988. doi: 10.1016/j.chembiol.2010.07.009

Jaakkola, P., Mole, D. R., Tian, Y. M., Wilson, M. I., Gielbert, J., Gaskell, S. J., .. . Ratcliffe, P. J. (2001). Targeting of HIF-alpha to the von Hippel-Lindau ubiquitylation complex by O2-regulated prolyl hydroxylation. Science, 292(5516), 468-472. doi: 10.1126/science.1059796

Jain, M., Rivera, S., Monclus, E. A., Synenki, L., Zirk, A., Eisenbart, J., . . . Chandel, N. S. (2013). Mitochondrial reactive oxygen species regulate transforming growth factor-beta signaling. J Biol Chem, 288(2), 770-777. doi: 10.1074/jbc.M112.431973

Jiang, B. H., Rue, E., Wang, G. L., Roe, R., \& Semenza, G. L. (1996). Dimerization, DNA binding, and transactivation properties of hypoxia-inducible factor 1. J Biol Chem, 271(30), 17771-17778.

Karamanlidis, G., Lee, C. F., Garcia-Menendez, L., Kolwicz, S. C., Jr., Suthammarak, W., Gong, G., .. . Tian, R. (2013). Mitochondrial complex I deficiency increases protein 
acetylation and accelerates heart failure. Cell Metab, 18(2), 239-250. doi: 10.1016/j.cmet.2013.07.002

Karuppagounder, S. S., Basso, M., Sleiman, S. F., Ma, T. C., Speer, R. E., Smirnova, N. A., . . . Ratan, R. R. (2013). In vitro ischemia suppresses hypoxic induction of hypoxia-inducible factor-1alpha by inhibition of synthesis and not enhanced degradation. J Neurosci Res, 91(8), 1066-1075. doi: 10.1002/jnr.23204

Lando, D., Peet, D. J., Gorman, J. J., Whelan, D. A., Whitelaw, M. L., \& Bruick, R. K. (2002). $\mathrm{FlH}-1$ is an asparaginyl hydroxylase enzyme that regulates the transcriptional activity of hypoxia-inducible factor. Genes Dev, 16(12), 1466-1471. doi: $10.1101 /$ gad.991402

Lee, S. R., Kwon, K. S., Kim, S. R., \& Rhee, S. G. (1998). Reversible inactivation of protein-tyrosine phosphatase 1B in A431 cells stimulated with epidermal growth factor. J Biol Chem, 273(25), 15366-15372.

Lei, H., \& Kazlauskas, A. (2014). A reactive oxygen species-mediated, self-perpetuating loop persistently activates platelet-derived growth factor receptor alpha. Mol Cell Biol, 34(1), 110-122. doi: 10.1128/MCB.00839-13

Mansfield, K. D., Guzy, R. D., Pan, Y., Young, R. M., Cash, T. P., Schumacker, P. T., \& Simon, M. C. (2005). Mitochondrial dysfunction resulting from loss of cytochrome c impairs cellular oxygen sensing and hypoxic HIF-alpha activation. Cell Metab, 1(6), 393-399. doi: 10.1016/j.cmet.2005.05.003

Masson, N., Singleton, R. S., Sekirnik, R., Trudgian, D. C., Ambrose, L. J., Miranda, M. X., . . Ratcliffe, P. J. (2012). The FIH hydroxylase is a cellular peroxide sensor 
that modulates HIF transcriptional activity. EMBO Rep, 13(3), 251-257. doi: 10.1038/embor.2012.9

Maxwell, P. H., Wiesener, M. S., Chang, G. W., Clifford, S. C., Vaux, E. C., Cockman, M. E., .. . Ratcliffe, P. J. (1999). The tumour suppressor protein VHL targets hypoxiainducible factors for oxygen-dependent proteolysis. Nature, 399(6733), 271-275. doi: $10.1038 / 20459$

Naranjo-Suarez, S., Carlson, B. A., Tsuji, P. A., Yoo, M. H., Gladyshev, V. N., \& Hatfield, D. L. (2012). HIF-independent regulation of thioredoxin reductase 1 contributes to the high levels of reactive oxygen species induced by hypoxia. PLoS One, 7(2), e30470. doi: 10.1371/journal.pone.0030470

Neal, A., Rountree, A., Kernan, K., Van Yserloo, B., Zhang, H., Reed, B. J., . . . Sweet, I. R. (2016). Real-time imaging of intracellular hydrogen peroxide in pancreatic islets. Biochem J, 473(23), 4443-4456. doi: 10.1042/BCJ20160481

Poitz, D. M., Augstein, A., Hesse, K., Christoph, M., Ibrahim, K., Braun-Dullaeus, R. C., . . . Schmeisser, A. (2014). Regulation of the HIF-system in human macrophages-differential regulation of HIF-alpha subunits under sustained hypoxia. Mol Immunol, 57(2), 226-235. doi: 10.1016/j.molimm.2013.10.001

Ratan, R. R., Murphy, T. H., \& Baraban, J. M. (1994). Oxidative stress induces apoptosis in embryonic cortical neurons. J Neurochem, 62(1), 376-379.

Safran, M., Kim, W. Y., O'Connell, F., Flippin, L., Gunzler, V., Horner, J. W., . . Kaelin, W. G., Jr. (2006). Mouse model for noninvasive imaging of HIF prolyl hydroxylase activity: assessment of an oral agent that stimulates erythropoietin production. Proc Natl Acad Sci U S A, 103(1), 105-110. doi: 10.1073/pnas.0509459103 
Salmeen, A., Andersen, J. N., Myers, M. P., Meng, T. C., Hinks, J. A., Tonks, N. K., \& Barford, D. (2003). Redox regulation of protein tyrosine phosphatase 1B involves a sulphenyl-amide intermediate. Nature, 423(6941), 769-773. doi: $10.1038 /$ nature 01680

Sang, N., Fang, J., Srinivas, V., Leshchinsky, I., \& Caro, J. (2002). Carboxyl-terminal transactivation activity of hypoxia-inducible factor 1 alpha is governed by a von Hippel-Lindau protein-independent, hydroxylation-regulated association with p300/CBP. Mol Cell Biol, 22(9), 2984-2992.

Semenza, G. L. (2012). Hypoxia-inducible factors: mediators of cancer progression and targets for cancer therapy. Trends Pharmacol Sci, 33(4), 207-214. doi: 10.1016/j.tips.2012.01.005

Semenza, G. L. (2014). Hypoxia-inducible factor 1 and cardiovascular disease. Annu Rev Physiol, 76, 39-56. doi: 10.1146/annurev-physiol-021113-170322

Semenza, G. L., \& Wang, G. L. (1992). A nuclear factor induced by hypoxia via de novo protein synthesis binds to the human erythropoietin gene enhancer at a site required for transcriptional activation. Mol Cell Biol, 12(12), 5447-5454.

Sheldon, R. A., Lee, C. L., Jiang, X., Knox, R. N., \& Ferriero, D. M. (2014). Hypoxic preconditioning protection is eliminated in HIF-1alpha knockout mice subjected to neonatal hypoxia-ischemia. Pediatr Res, 76(1), 46-53. doi: 10.1038/pr.2014.53

Smirnova, N. A., Rakhman, I., Moroz, N., Basso, M., Payappilly, J., Kazakov, S., . . Gazaryan, I. G. (2010). Utilization of an in vivo reporter for high throughput identification of branched small molecule regulators of hypoxic adaptation. Chem Biol, 17(4), 380-391. doi: 10.1016/j.chembiol.2010.03.008 
Sweet, I. R., Cook, D. L., DeJulio, E., Wallen, A. R., Khalil, G., Callis, J., \& Reems, J. (2004). Regulation of ATP/ADP in pancreatic islets. Diabetes, 53(2), 401-409.

Sweet, I. R., Cook, D. L., Wiseman, R. W., Greenbaum, C. J., Lernmark, A., Matsumoto, S., ... Krohn, K. A. (2002). Dynamic perifusion to maintain and assess isolated pancreatic islets. Diabetes Technol Ther, 4(1), 67-76. doi: $10.1089 / 15209150252924111$

Sweet, I. R., \& Gilbert, M. (2006). Contribution of calcium influx in mediating glucosestimulated oxygen consumption in pancreatic islets. Diabetes, 55(12), 3509-3519. doi: $10.2337 / \mathrm{db} 06-0400$

Sweet, I. R., Khalil, G., Wallen, A. R., Steedman, M., Schenkman, K. A., Reems, J. A., . . . Callis, J. B. (2002). Continuous measurement of oxygen consumption by pancreatic islets. Diabetes Technol Ther, 4(5), 661-672. doi: $10.1089 / 152091502320798303$

Tan, S., Wood, M., \& Maher, P. (1998). Oxidative stress induces a form of programmed cell death with characteristics of both apoptosis and necrosis in neuronal cells. $J$ Neurochem, 71(1), 95-105.

Taylor, C. T. (2008). Mitochondria and cellular oxygen sensing in the HIF pathway. Biochem J, 409(1), 19-26. doi: 10.1042/BJ20071249

Wang, G. L., Jiang, B. H., Rue, E. A., \& Semenza, G. L. (1995). Hypoxia-inducible factor 1 is a basic-helix-loop-helix-PAS heterodimer regulated by cellular $\mathrm{O} 2$ tension. Proc Natl Acad Sci U S A, 92(12), 5510-5514. 
Wang, G. L., \& Semenza, G. L. (1993). General involvement of hypoxia-inducible factor 1 in transcriptional response to hypoxia. Proc Natl Acad Sci U S A, 90(9), 43044308.

Weidemann, A., Bernhardt, W. M., Klanke, B., Daniel, C., Buchholz, B., Campean, V., . . . Willam, C. (2008). HIF activation protects from acute kidney injury. J Am Soc Nephrol, 19(3), 486-494. doi: 10.1681/ASN.2007040419

Wood, S. M., Gleadle, J. M., Pugh, C. W., Hankinson, O., \& Ratcliffe, P. J. (1996). The role of the aryl hydrocarbon receptor nuclear translocator (ARNT) in hypoxic induction of gene expression. Studies in ARNT-deficient cells. J Biol Chem, 271(25), 15117-15123.

Zhang, H., Bosch-Marce, M., Shimoda, L. A., Tan, Y. S., Baek, J. H., Wesley, J. B., . . Semenza, G. L. (2008). Mitochondrial autophagy is an HIF-1-dependent adaptive metabolic response to hypoxia. J Biol Chem, 283(16), 10892-10903. doi: 10.1074/jbc.M800102200 
A

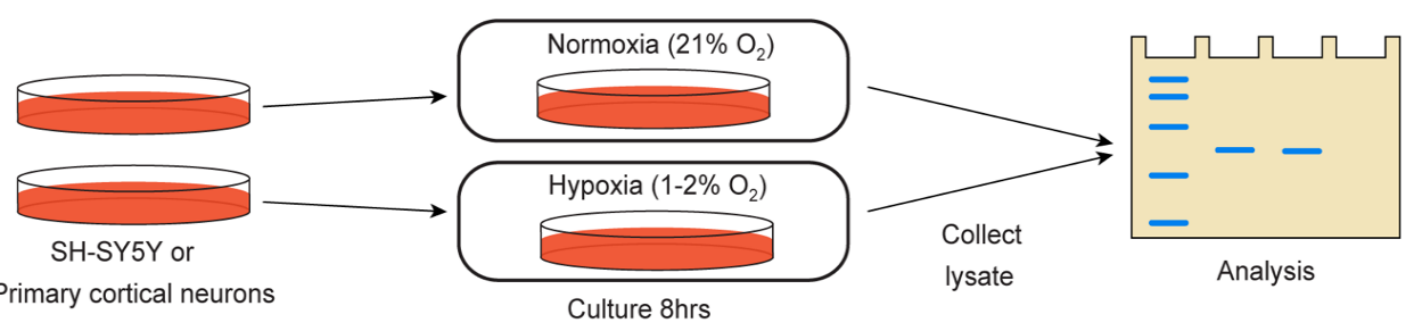

B

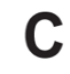

SH-SY5Y

Norm Hypo Kda
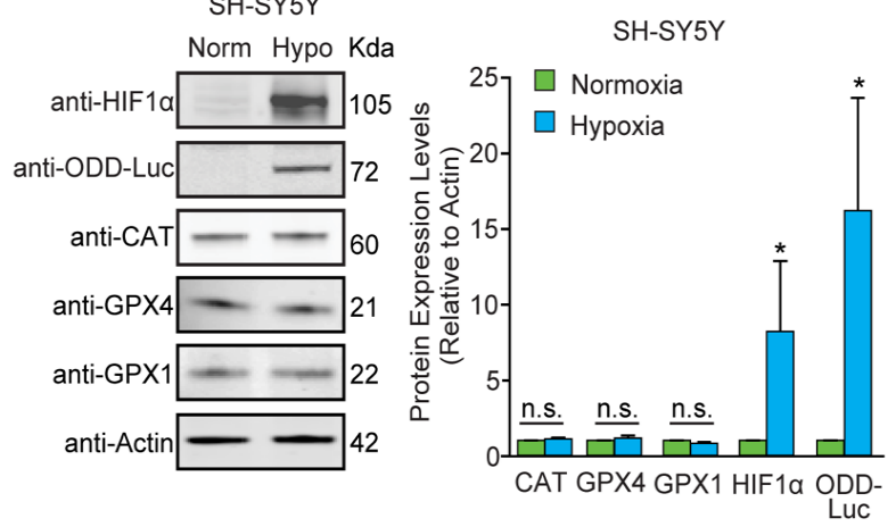

D

E

SH-SY5Y

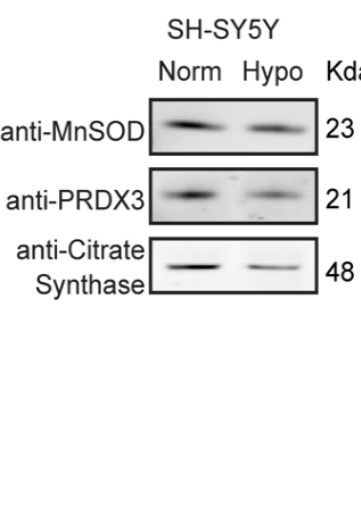

$\mathbf{F}$

Primary

G

Primary

cortical neurons

$\mathrm{H}$

cortical neurons
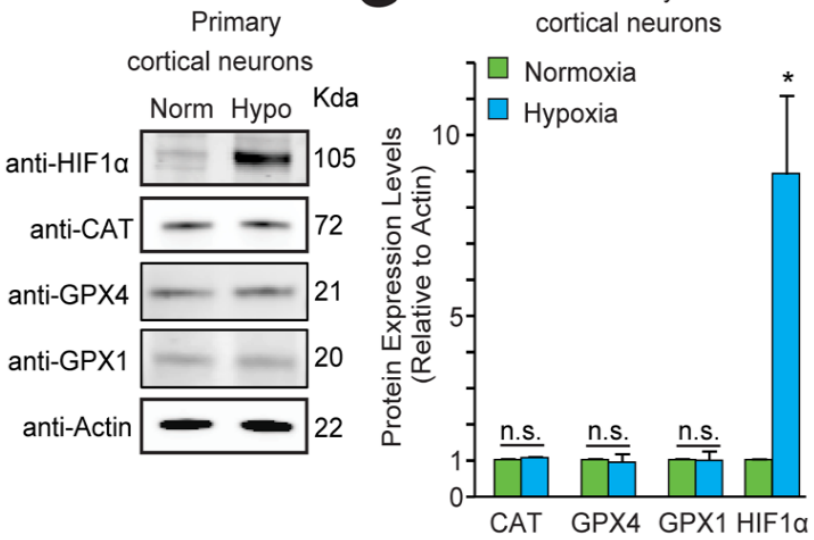

Primary
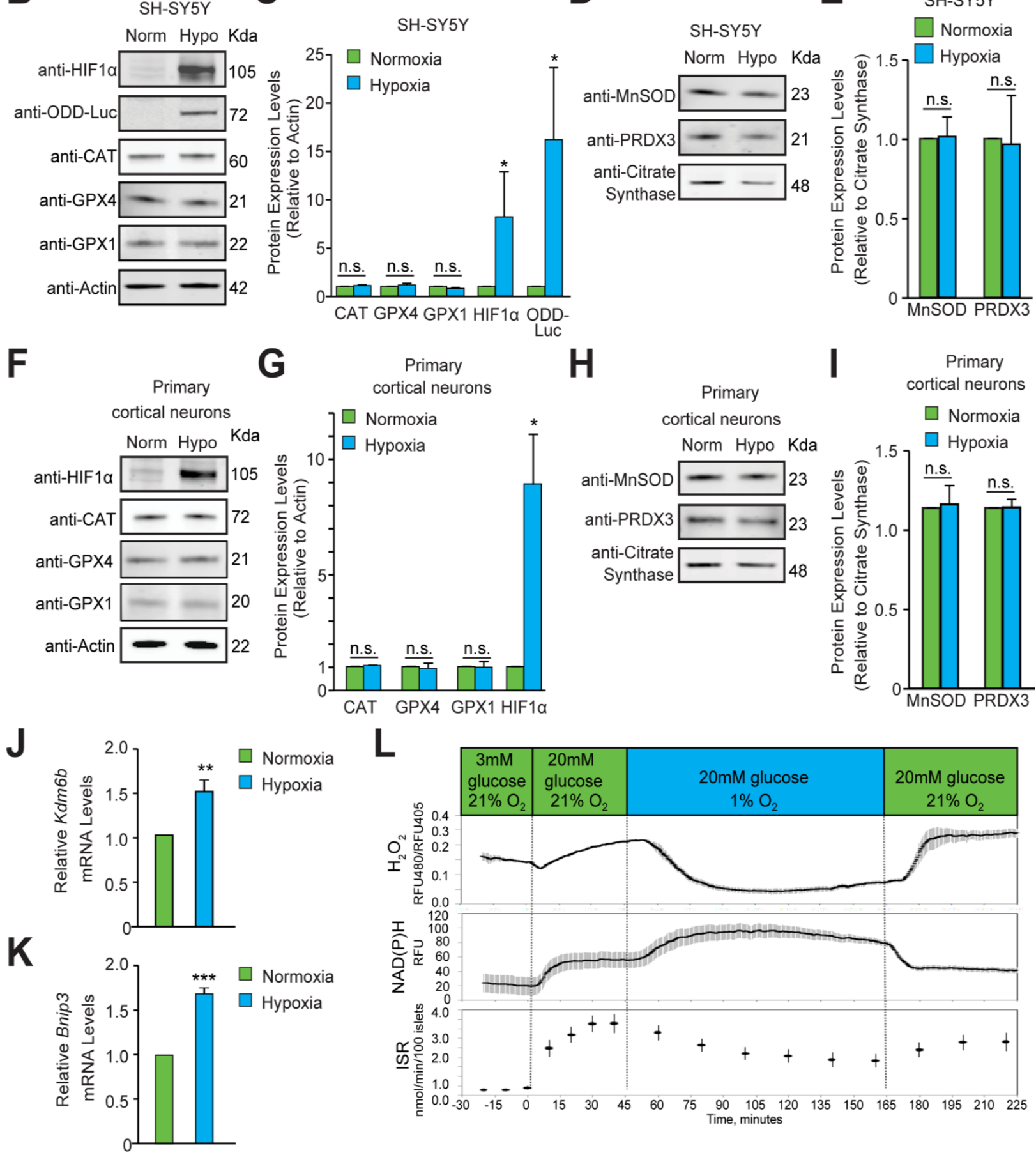
Figure 1. Hypoxia did not induce homeostatic increases in antioxidant enzymes or increase peroxide levels (A) Experimental approach employed to examine changes in the protein levels of endogenous antioxidant enzymes in hypoxia. (B-I) Immunoblots of catalase (peroxisome), GPX1 and GPX4 (cytosol and mitochondria) or MnSOD and PRDX3 (mitochondria) in (B-E) SH-SY5Y ODD Luc. cells that stably overexpressed ODD (HIF Oxygen Dependent Domain-luciferase fusion) or (F-I) PCNs exposed to normoxia or hypoxia for $8 \mathrm{~h}$. The protein levels of catalase, GPX4 and GPX1 were normalized to actin, while those of MnSOD and PRDX3 were normalized to the mitochondrial protein, citrate synthase. A monoclonal antibody to luciferase (indicated as anti-ODD-Luc. in the figure) was used to detect changes in ODD-luciferase protein levels in SH-SY5Y ODD-Luc. cells. (J-K) Pancreatic islets were exposed to hypoxia for $2 \mathrm{~h}$ and then were lysed and processed for mRNA expression analysis of HIF1 $\alpha$ target genes, Kdm6b and Bnip3. The densitometric data and gene expression data were pooled from three independent experiments an presented as mean \pm SD. The densitometric data and gene expression data were statistically analysed using Student's t test (B-K). (n.s.) indicates non-significant difference, $\left({ }^{* *}\right)$ indicates $p<0.01$ and $\left(^{* * *}\right)$ indicates $p<0.001$ with respect to respective normoxia controls. (L) Hypoxia leads to a large decrease in $\mathrm{H}_{2} \mathrm{O}_{2}$ levels (top), increased $\mathrm{NAD}(\mathrm{P}) \mathrm{H}$ (middle), and decreased insulin secretion (bottom). Glucose stimulation by 20 $\mathrm{mM}$ glucose was added as reference, and oxygen levels were changed using an artificial gas equilibration device placed inline in the flow system. All three experiments were carried out separately, but using the same flow culture system. 


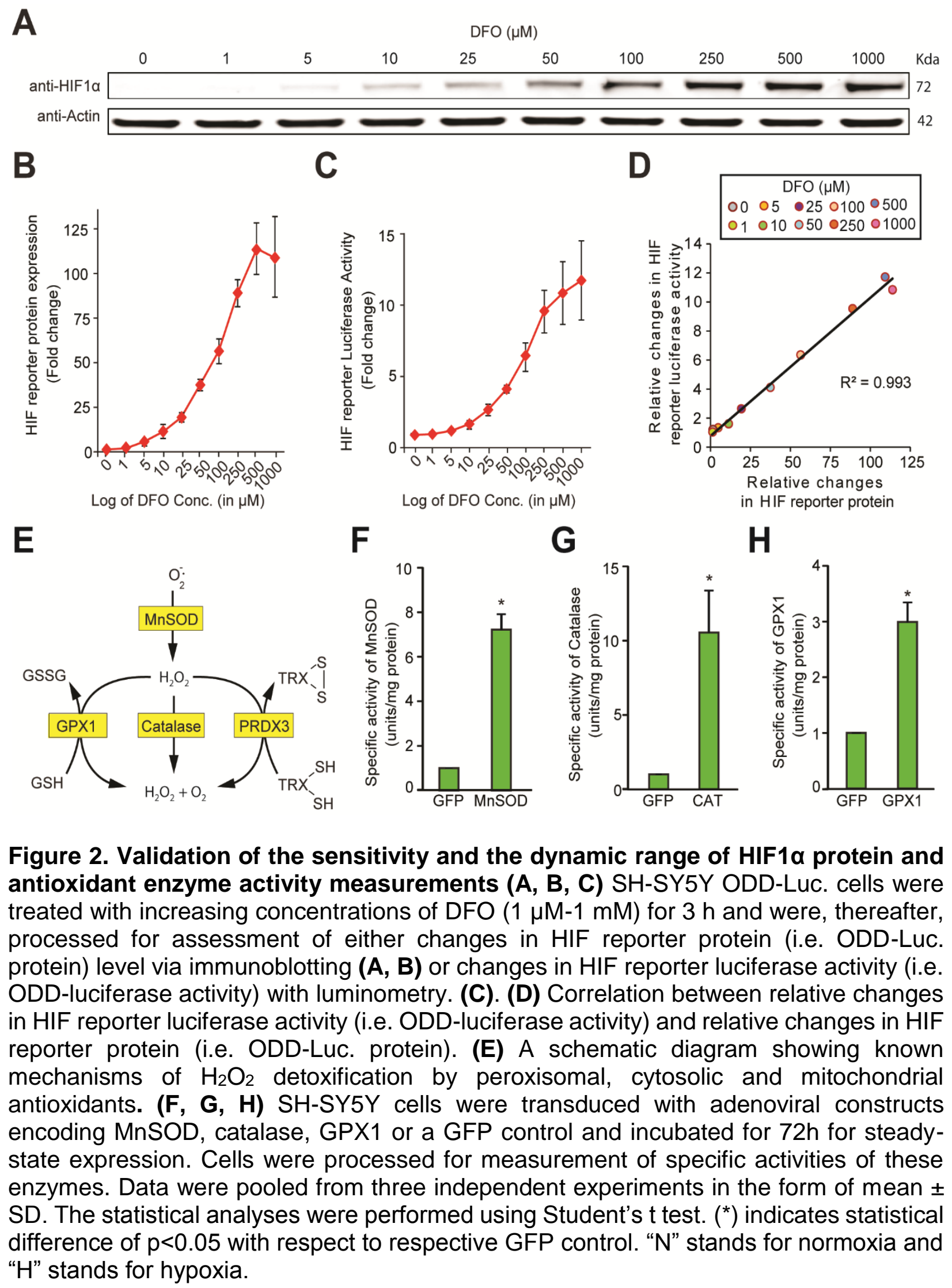




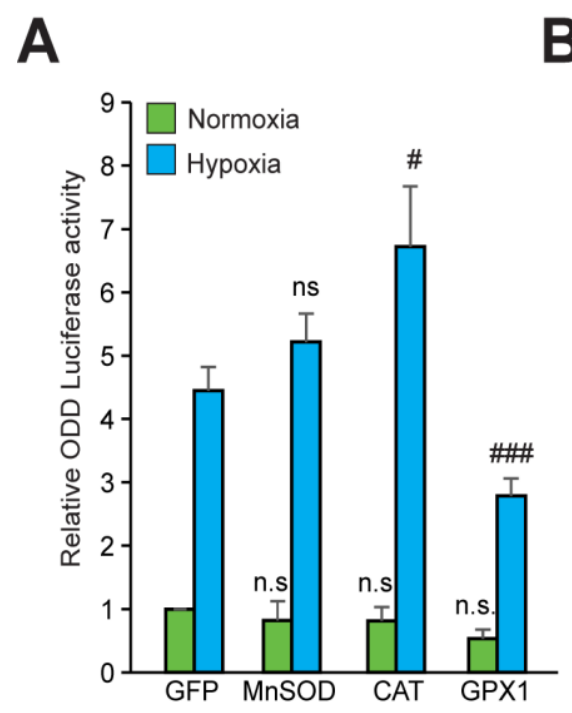

D



B


E



F

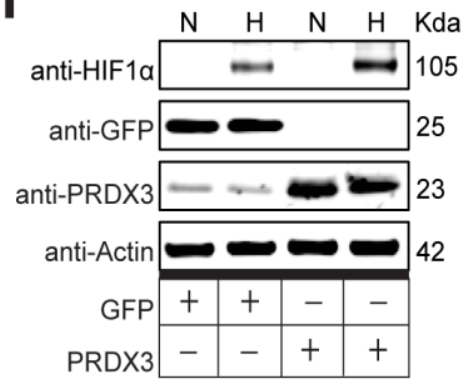

Figure 3. The stabilization of HIF1a is not oxidant-initiated in hypoxia (A, B, C, D) SH-SY5Y cells stably expressing ODD-luciferase were transduced with adenoviruses encoding distinct antioxidant enzymes for $72 \mathrm{~h}$ and then exposed to normoxia or hypoxia in parallel and were either processed for luciferase activity assay ( $A$ measure of quantitative changes in ODD) (A, B) or immunoblot analysis (A measure of quantitative changes in protein levels of ODD and HIF1 $\alpha)(C, D)$. (E, F) Mouse primary neurons were transduced with adenoviral vectors encoding distinct antioxidant enzymes or GFP for 48h and then exposed to normoxia or hypoxia in parallel for $4 \mathrm{~h}$. Two way ANOVA with Bonferroni post-test was used for all comparisons. (n.s.) indicates non-significant difference with respect to GFP control under normoxia while (ns), (\#) and (\#\#\#) indicate non-significant difference and the statistical differences of $p<0.05$, and $p<0.001$, respectively, with respect to GFP control in hypoxia. All Western blot experiments were performed as three independent sets and a representative blot of each was shown in the figure. 

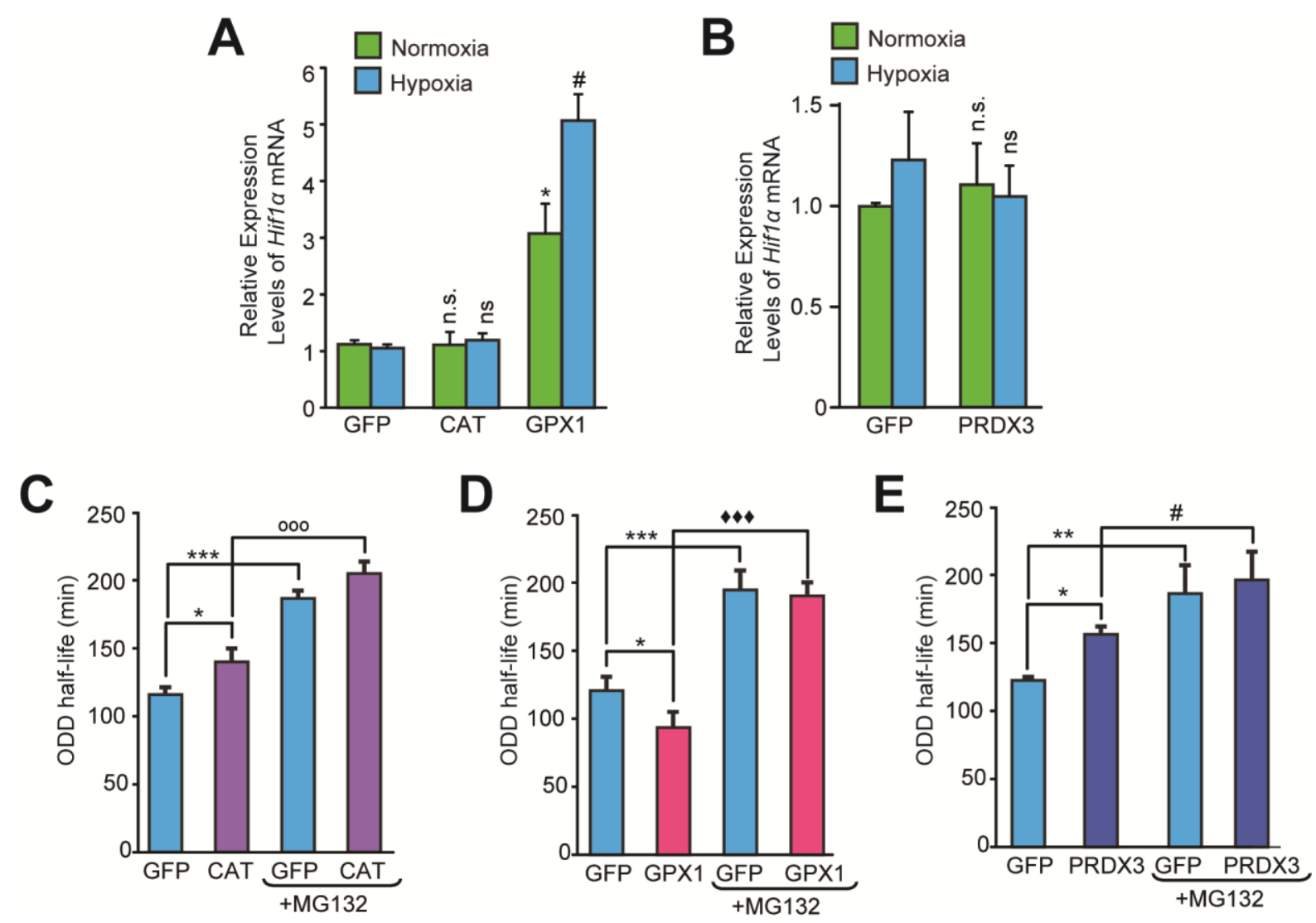

Figure 4. Divergent changes in HIF1a protein levels induced by antioxidant enzymes capable of scavenging peroxide cannot be attributed to differential changes in HIF1a mRNA synthesis or stability (A, B) Relative changes in Hif1a mRNA in SH-SY5Y cells in response to forced expression of various antioxidant enzymes. Data were pooled from three independent experiments in the form of mean \pm SD. One way ANOVA with Dunnett's post-test was used for comparing cells expressing catalase or GPX1 with respect to cells expressing GFP and Student's t test was used for comparing cells expressing PRDX3 with respect to GFP. (n.s.) indicates non-significant difference with respect to respective GFP controls under normoxia while (ns) and (\#) indicate nonsignificant difference and the statistical difference of $p<0.05$, respectively, with respect to GFP control in hypoxia. (C, D, E) Changes in half-life of HIF1a in SH-SY5Y ODD-Luc cells expressing catalase or GPX1 or PRDX3 with respect to that of respective GFP controls in hypoxia. ODD Half-life was assessed by performing a pulse chase experiment by adding $35 \mu \mathrm{M}$ cycloheximide at every twenty minutes for a total of four hours using luciferase activity assay in SH-SY5Y cells expressing these antioxidants pre-treated either with or without $10 \mu \mathrm{M}$ MG132. Data were pooled from three independent experiments in the form of mean \pm SD. Two way ANOVA with Bonferroni's post-test was used for statistical analysis. $\left({ }^{*}\right),\left({ }^{* *}\right)$, and $\left({ }^{* * *}\right)$ indicate statistical differences of $p<0.05$, $p<0.01$ and $p<0.001$ with respect to respective GFP controls in hypoxia. $\left({ }^{\circ 00}\right),\left({ }^{* * *}\right)$ and $(\#)$ represent statistical differences of $p<0.001$ w.r.t CAT, $p<0.001$ w.r.t GPX1 and $p<0.05$ w.r.t PRDX3, respectively. 

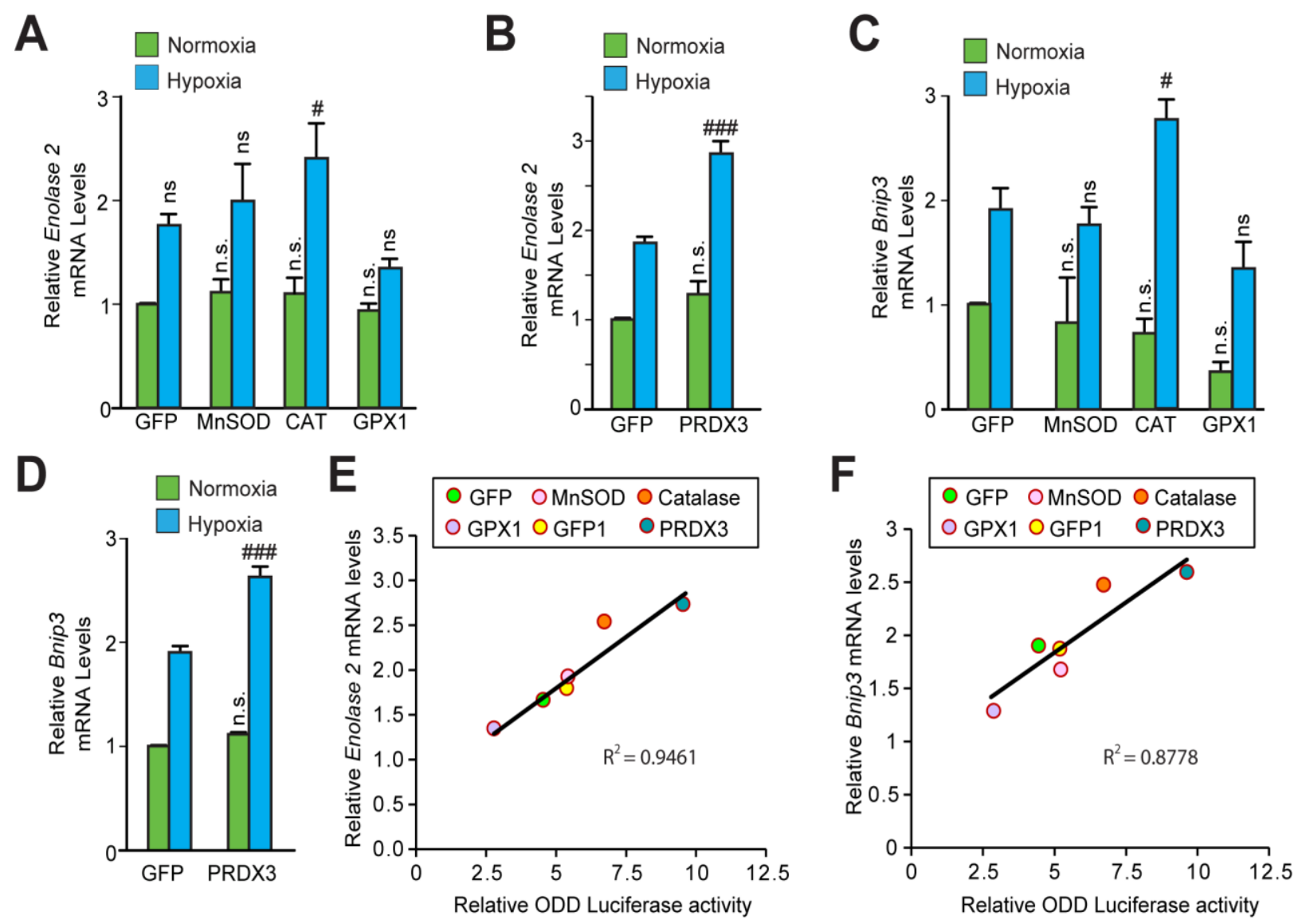

Figure 5. The transcriptional activity of HIF1a is not oxidant-initiated in hypoxia. Relative changes in mRNA levels of HIF1a target genes (A, B) Enolase2 and (C, D) Bnip3 in SH-SY5Y cells expressing various antioxidant enzymes as compared to that of respective GFP controls. Data were pooled from three independent experiments in the form of mean \pm SD. One way ANOVA with Dunnett's post-test was used for comparing the statistical difference between cells expressing MnSOD, catalase or GPX1 with respect to that of GFP control and Student's t test was used to compare the statistical difference between cells expressing PRDX3 with that of GFP control. (n.s.) indicates non-significant difference with respect to respective GFP controls under normoxia only while (ns), (\#) and $(\# \# \#)$ indicate non-significant difference, and the statistical differences of $p<0.05$, and $\mathrm{p}<0.001$, respectively, with respect to GFP control in hypoxia. (E, F) Correlation between relative changes in either Enolase2 or Bnip3 and relative ODD-luciferase activities. 


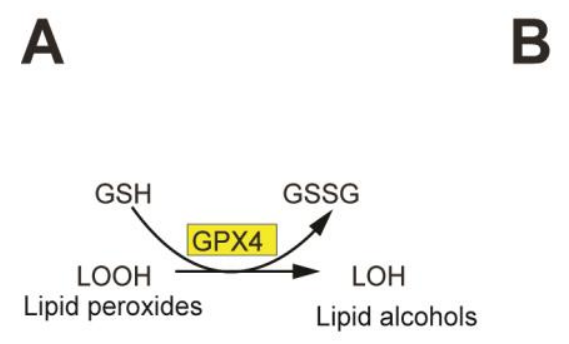

C

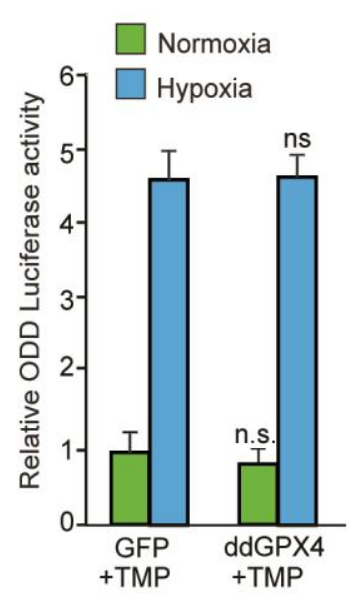

$\mathbf{F}$

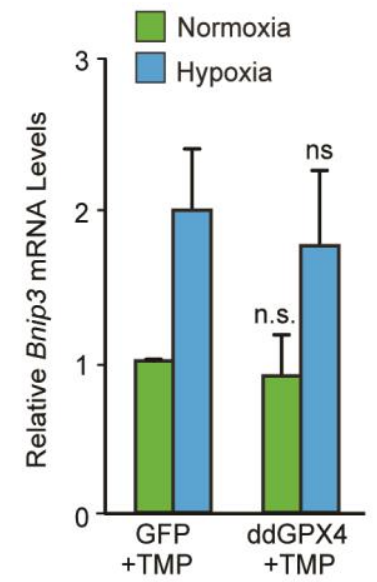

B

D

G


E
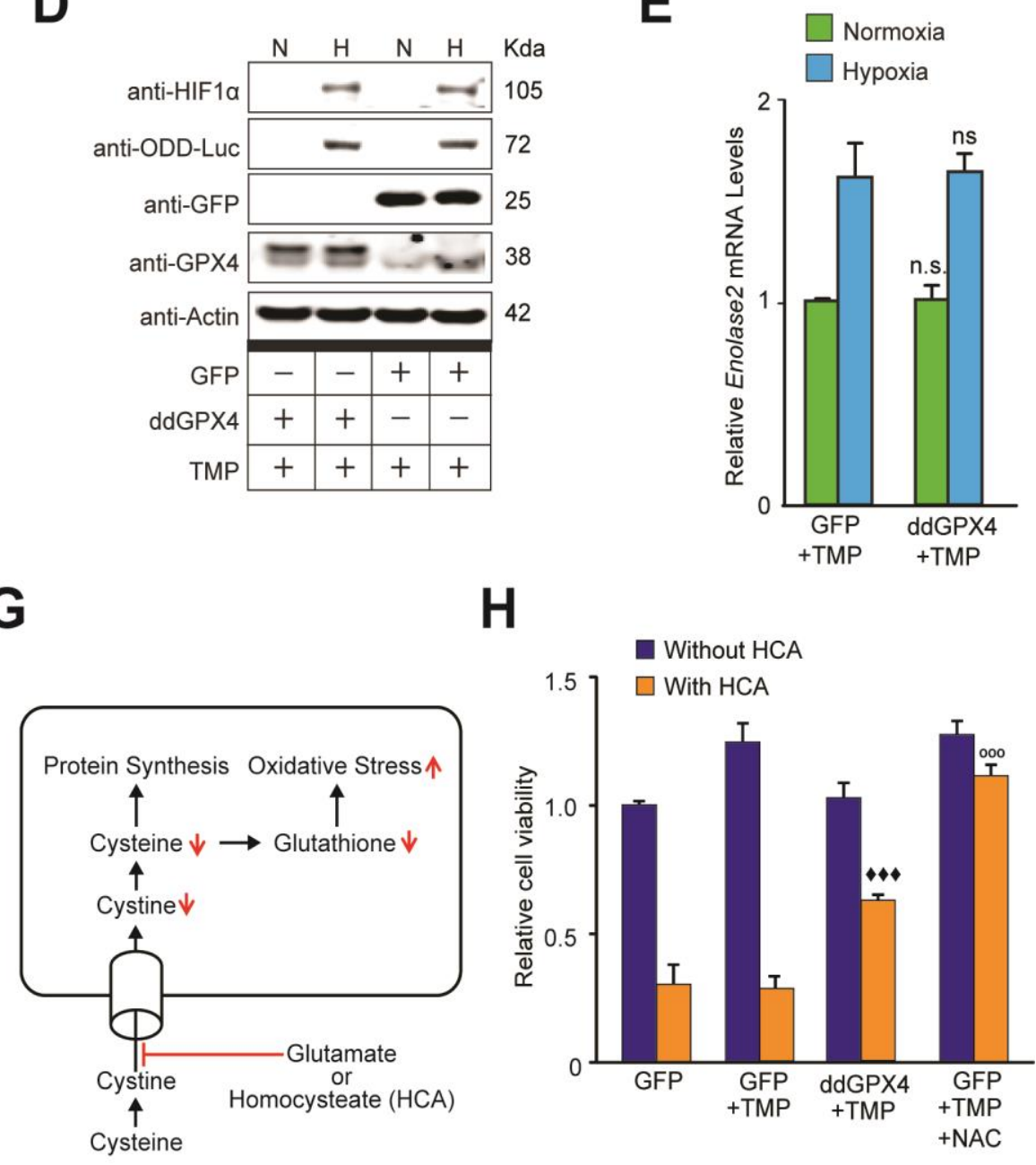

H

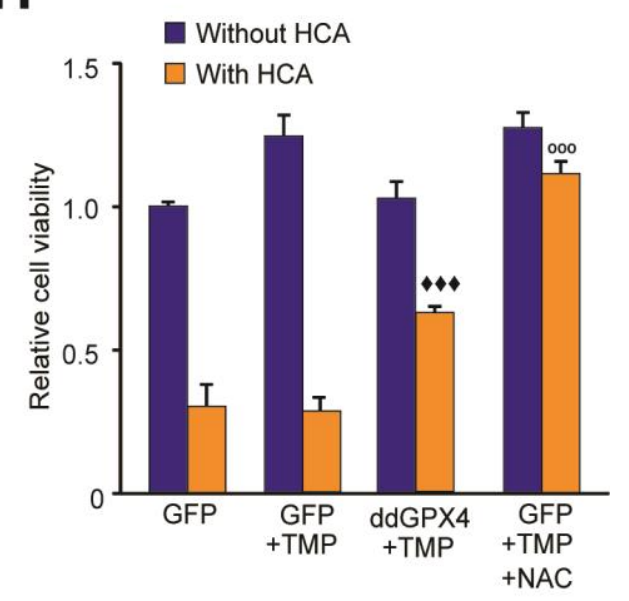

Figure 6. Reactive lipid species do not regulate HIF1a stabilization or its transcriptional activity in hypoxia (A) A schematic diagram showing that GPX4 converts lipid hydroperoxides into lipid alcohols using GSH as a cofactor. (B) A schematic showing regulated protein expression of GPX4 fusion containing an optimized destabilization domain when exposed to the antibiotic, Trimethoprim (TMP). Reversible stability of GPX4 protein was conferred by fusing its coding sequence to a destabilization domain sequence (mutants of $E$. Coli dihydrofolate reductase). Accordingly, GPX4 protein possessing the destabilization domain is degraded resulting in low steady levels of GPX4. 
Trimethoprim binds to and neutralizes the destabilization domain stabilizing GPX4 protein in a dose dependent manner. (C, D) SH-SY5Y ODD-Luc cells were transduced with adenoviral vectors encoding a destabilized form of GPX4 (ddGPX4) or GFP and then exposed to normoxia/hypoxia and were either processed for luciferase activity assay (C) or immunoblotting (D). $10 \mu \mathrm{M}$ TMP was added to ddGPX4 expressing cells after 60h of adenoviral incubation for $12 \mathrm{~h}$ in order to achieve stabilized GPX4 expression. (E, F) Relative changes in mRNA levels of HIF1a target genes, Enolase2 and Bnip3 in SHSY5Y cells. (G) A schematic diagram depicting the glutathione depletion model of oxidative stress. (H) PCNs were transduced with GFP/GPX4 for $24 \mathrm{~h}$ and then treated with $5 \mathrm{mM} \mathrm{HCA}$. Cells were simultaneously treated with $10 \mu \mathrm{M}$ TMP. Then, cells were incubated for $24 \mathrm{~h}$ to induce oxidative stress. Thereafter, viability of cells was measured via the MTT assay. $100 \mu \mathrm{M}$ NAC was used as positive control. The final values were pooled as mean \pm S.D. of three independent experiments. Two way ANOVA with Bonferroni's post-test was used for statistical analyses. One way ANOVA with Dunnett's post-test was used for comparing DCF fluorescence and viability. (n.s.), $\left(^{*}\right)$ and $\left({ }^{* * *}\right)$ indicate non-significant difference, and the statistical differences of $p<0.05$, and $p<0.001$, respectively, with respect to GFP control under normoxia while (ns), (\#) and (\#\#\#) indicate non-significant difference, and the statistical differences of $p<0.05$, and $p<0.001$, respectively, with respect to GFP control in hypoxia. $\left({ }^{\circ \circ}\right)$ indicates statistical difference of $p<0.001$ with respect to GFP treated with HCA only while (**) indicates statistical difference of $p<0.001$ with respect to GFP treated with both TMP and HCA. 